\title{
Architecture, structures and construction 1, 1 (2021)
}

\author{
Paulo Jorge de Sousa Cruz ${ }^{1}$ João Paulo C. Rodrigues ${ }^{2}$
}

Published online: 2 November 2021

(c) The Author(s), under exclusive licence to Springer Nature Switzerland AG 2021

It is our great pleasure to present the first issue of Architecture, Structures and Construction, a hitherto non-existing platform for nurturing the synergy of the disciplines of architecture, building and structural engineering by tracking, promoting, and advancing the development of these areas and by opening a wide range of opportunities in the joint pursuit of new concepts, applications and challenges, with an emphasis on collaboration and innovation.

Architecture, Structures and Construction is dedicated to the recent advances in the art, theory and practice of architectural structures, contributing to the betterment of the built environment by addressing current challenges. The journal gives preference to manuscripts of academics and practitioners with an integrated and holistic vision of those fields. This encompasses: original articles, review papers, opinion papers, technical notes, discussions, case studies and book reviews. Besides the regular issues, the journal will look for themed issues dedicated to specific topics of relevance to a wide international and multidisciplinary readership.

The journal aims to become the leading platform, informing the latest achievements and connecting academics and researchers, architects, structural and construction engineers, builders and building consultants, construction industry persons builders and building consultants, product manufacturers, material suppliers, project managers and others.
For this first issue outstanding papers have been selected following a strict double-blind peer review process by top experts in the field. The papers focus on different aspects of structural design, eco-materials and material characterisation, numerical analysis, field experiments and modelling. We would like to sincerely thank all authors and reviewers for their work to make this first issue a reality.

We would like also to express our deepest gratitude to Springer Nature for believing in this project and for the professional support of an enthusiastic team, namely: Nathalie Jacobs, Executive Editor; Cynthia Feenstra, Assistant Editor; and Deborah van der Gaag, Implementation Manager and Editorial Operations Coordinator.

We are truly grateful to the Associate Editors, Wan-Ki Chow, Marie Frier Hvejsel and Caitlin Mueller, for their ongoing commitment and endeavours towards making the journal a success. We highly appreciate also the support of all Editorial and Industrial Board members.

We look forward to working with you all for many coming issues and volumes of the journal.

P. J. S. Cruz \& J. P. C. Rodrigues

The Editors-in-Chief, June 2021

Paulo Jorge de Sousa Cruz

pcruz@eaad.uminho.pt

1 School of Architecture, Art and Design, University of Minho, Guimarães, Portugal

2 Faculty of Sciences and Technology, University of Coimbra, Coimbra, Portugal 